Organ der Bundesanstalt für Materialforschung und -prüfung Berlin (BAM)

\section{BRUCHMECHANIK}

Einfluss von Kerbschärfe und Anriss auf $\mathrm{K}_{\mathrm{I}}$

\section{AESSERUNDGANG:} CONTROL

\section{TRIBOLOGISCHE PRÜFUNG}

Thermische igenschaften von Gleitpaarungen

\section{MECHANISCHE WERKSTOFF- PRÜFUNG}

ermisch-mechanier Versuchsstand

Eigenschaften stenitischer Stähle

\title{
MATERIALS TESTING
}

\section{Werkstoffe und Bauteile, \\ Technologien und Anwendungen}

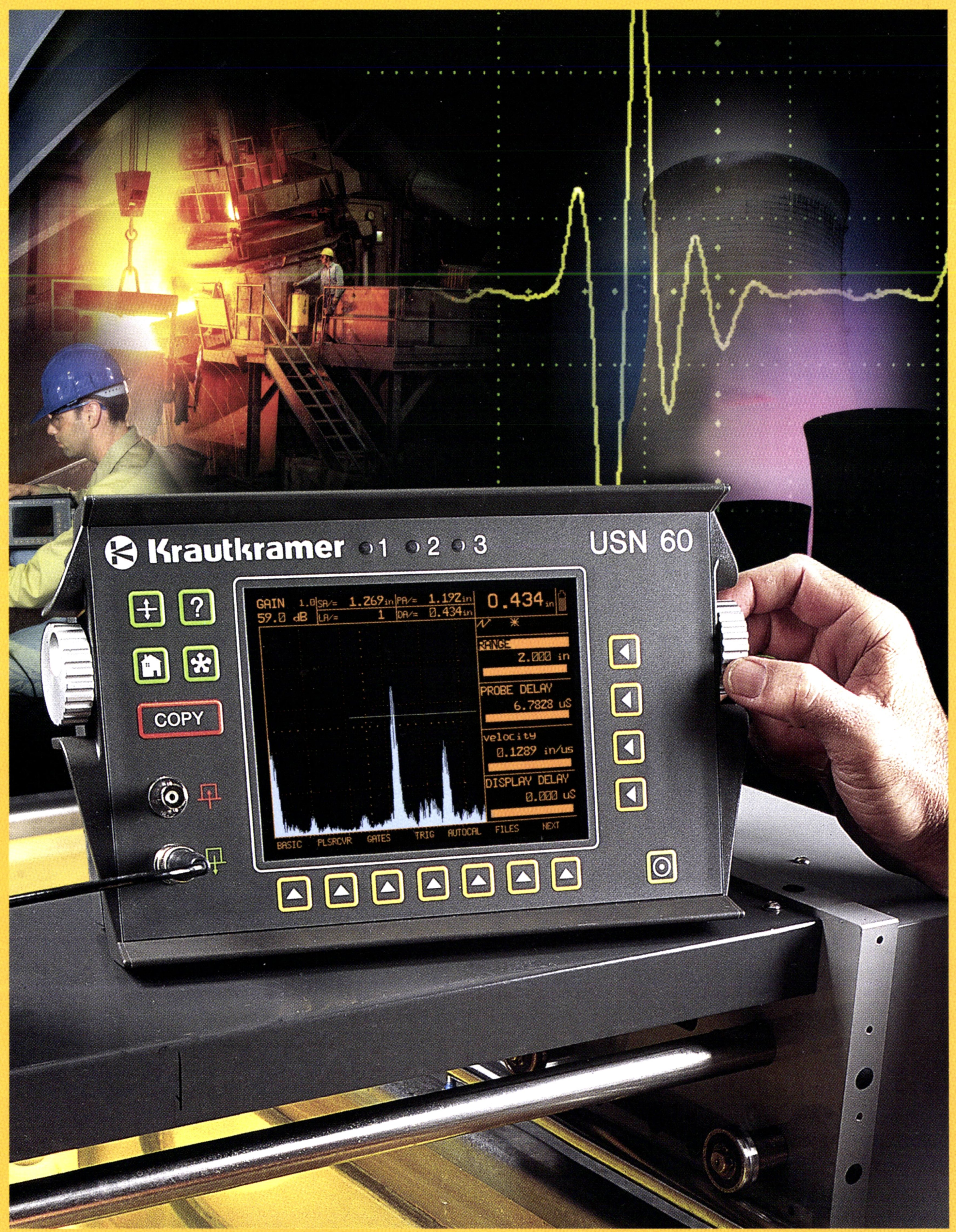




\section{Sicherheit rund ums Auto}

Von Stoffen bis hin zu Lackierungen oder der Festigkeit von Blechen, von Armaturenbrettern bis hin zu Türverriegelungen, von Achsen und Motoren bis hin zu ganzen

Fahrzeugen gewährleistet Instron die Sicherheit von mehr als 1.500 Komponenten und Werkstoffen im Automobilbau. Sogar bis hin zum Asphalt unter den Rädern...und den Brücken, auf denen diese Fahrzeuge fahren.

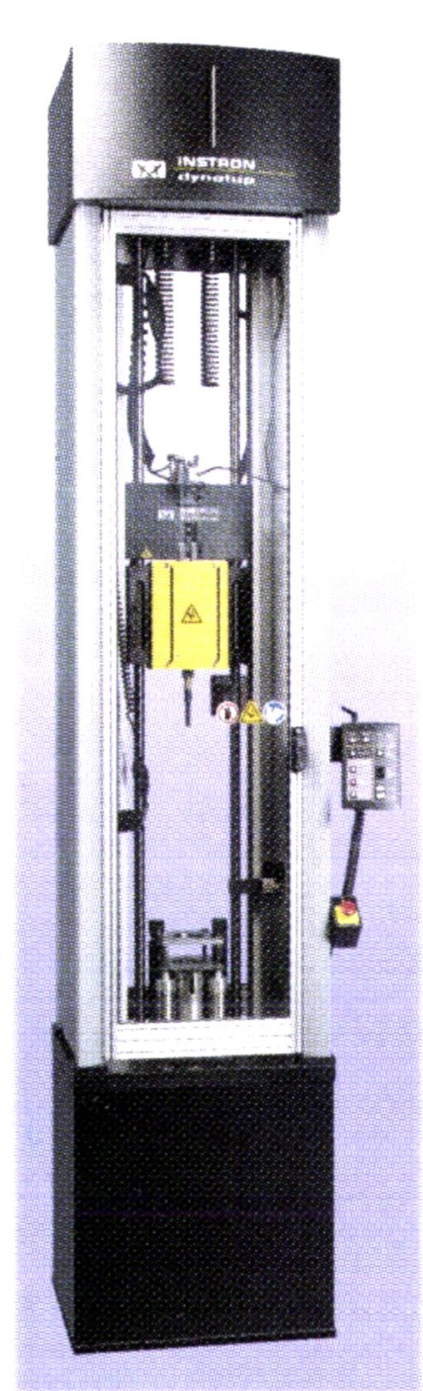

Instrumentiertes Fallwerk

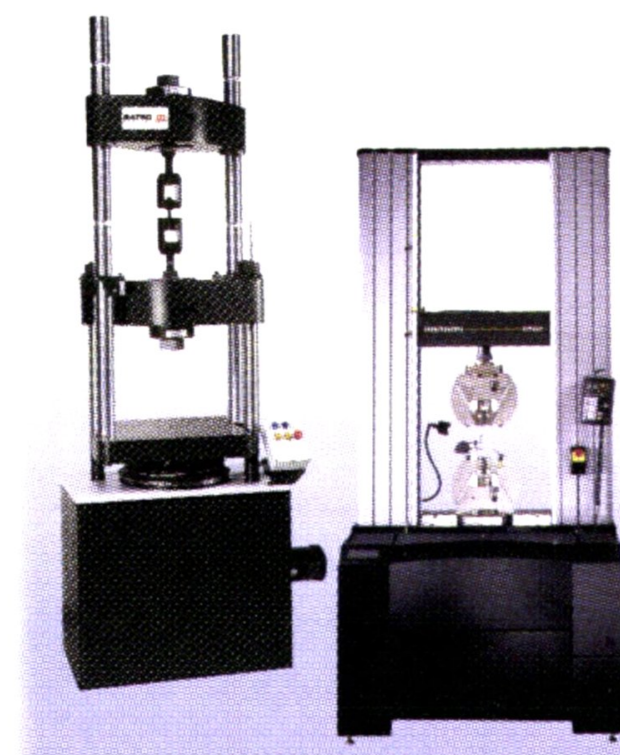

Universalprüfsysteme

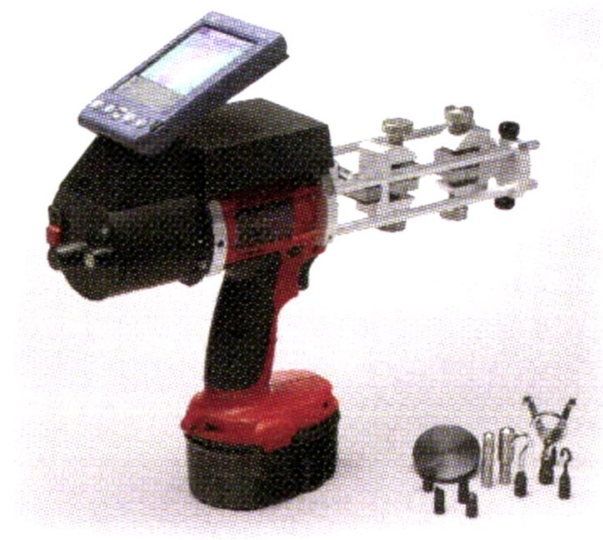

Handprüfgerät

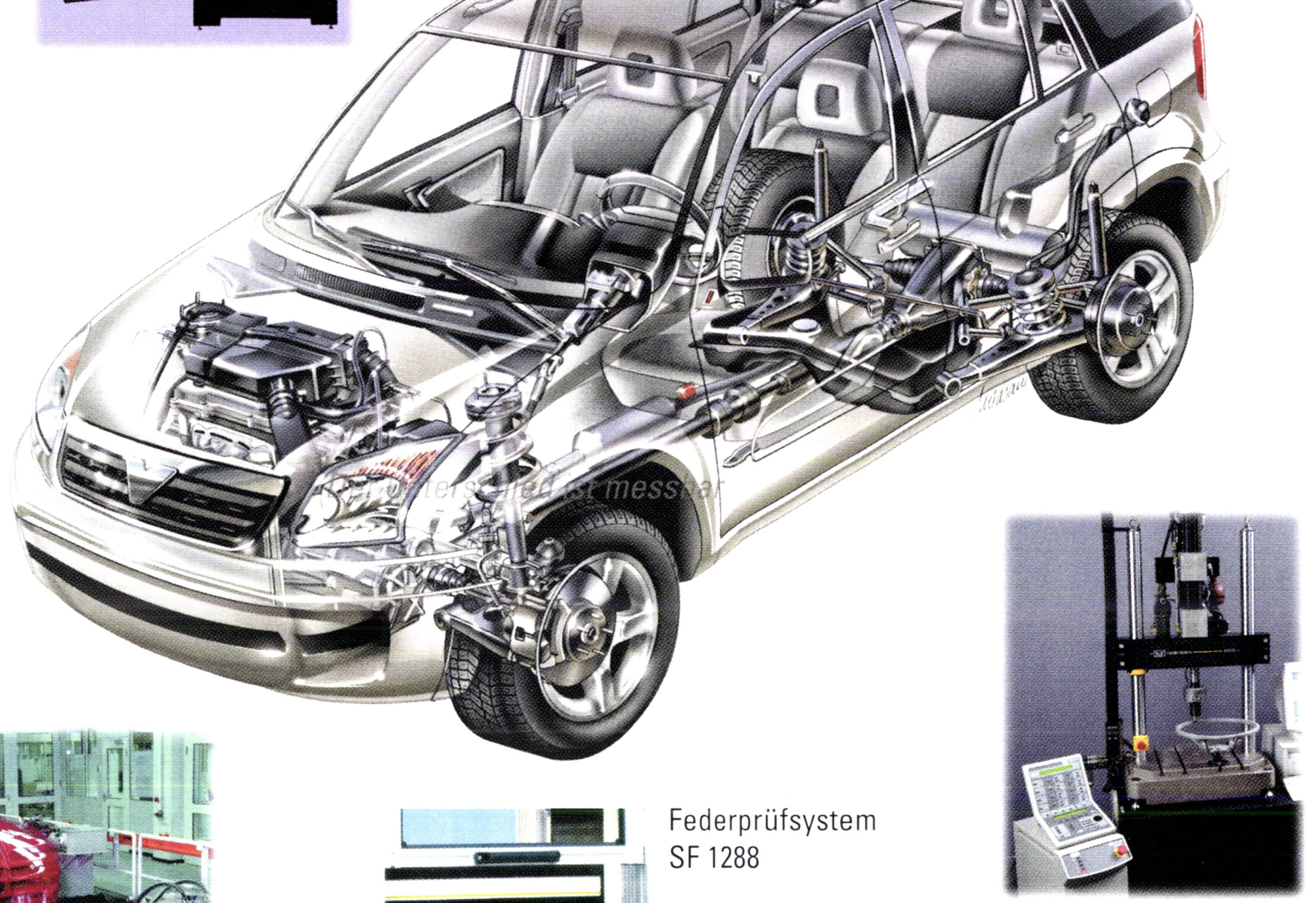

Servohydraulische Prüfsysteme aus der Serie 8800

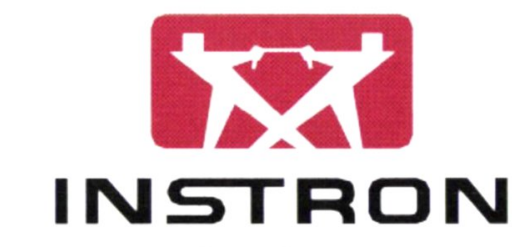

www.instron.com

Instron Germany

Landwehstrasse 55

D-64293 Darmstadt,

Deutschland

Tel: +496151324600

Fax:+496151324699

zu Ihrem Standard. Instron ist der richtige Partner für kritische Anwendungen in allen Branchen. Informieren Sie sich auf unserer Website unter www.instron.com. 